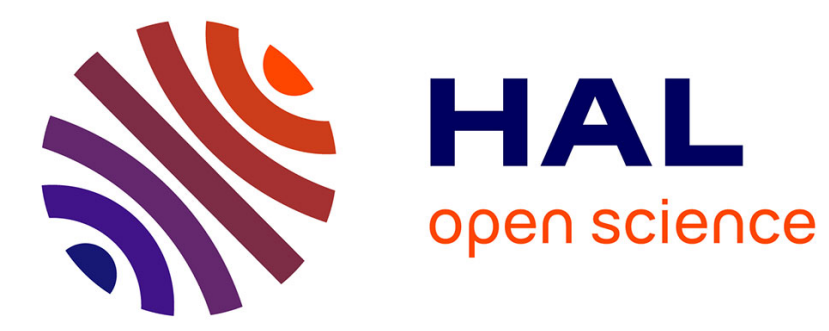

\title{
UV NANOSECOND LASER-INDUCED BIREFRINGENCE IN LBG GLASSES
}

Dominique Vouagner, Camille Coussa, Valeria Califano, Christine Martinet, Bernard Champagnon, V. Sigaev

\section{- To cite this version:}

Dominique Vouagner, Camille Coussa, Valeria Califano, Christine Martinet, Bernard Champagnon, et al.. UV NANOSECOND LASER-INDUCED BIREFRINGENCE IN LBG GLASSES. Philosophical Magazine, 2007, 87 (3-5), pp.535-542. 10.1080/14786430600900104 . hal-00513739

\section{HAL Id: hal-00513739 \\ https://hal.science/hal-00513739}

Submitted on 1 Sep 2010

HAL is a multi-disciplinary open access archive for the deposit and dissemination of scientific research documents, whether they are published or not. The documents may come from teaching and research institutions in France or abroad, or from public or private research centers.
L'archive ouverte pluridisciplinaire HAL, est destinée au dépôt et à la diffusion de documents scientifiques de niveau recherche, publiés ou non, émanant des établissements d'enseignement et de recherche français ou étrangers, des laboratoires publics ou privés. 


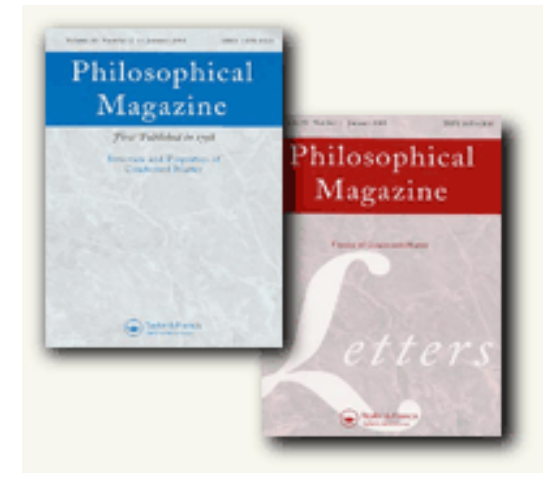

\section{UV NANOSECOND LASER-INDUCED BIREFRINGENCE IN LBG GLASSES}

\begin{tabular}{|r|l|}
\hline Journal: & Philosophical Magazine \& Philosophical Magazine Letters \\
\hline Manuscript ID: & TPHM-06-Apr-0110.R1 \\
\hline Journal Selection: & Philosophical Magazine \\
\hline Date Submitted by the & 16 -Jun-2006 \\
\hline Complete List of Authors: & $\begin{array}{l}\text { vouagner, dominique; LPCML UCBLYONI } \\
\text { COUSSA, Camille; LPCML UCB LYON I } \\
\text { Califano, Valeria; LPCML UCB LYON I; University of Naples Federico } \\
\text { II, Material and Production Engineering } \\
\text { Martinet, Christine; University Lyon1-UMR5620 CNRS, LPCML } \\
\text { champagnon, bernard; University Lyon1-UMR5620 CNRS, LPCML } \\
\text { Sigaev, V.; Mendeleev University of Chemical Technology of Russia }\end{array}$ \\
\hline Keywords: & $\begin{array}{l}\text { glass, irradiation effects, lasers, non-linear optics, oxide glasses, } \\
\text { Raman spectroscopy }\end{array}$ \\
\hline Keywords (user supplied): & \multicolumn{2}{|l}{} \\
\hline
\end{tabular}

\section{S ScholarONE" Manuscript Central}




\title{
UV NANOSECOND LASER-INDUCED BIREFRINGENCE IN LBG GLASSES
}

\author{
*D. Vouagner, ${ }^{*}$ C. Coussa, ${ }^{* \dagger}$ V. Califano, ${ }^{*}$ C. Martinet, ${ }^{*}$ B. Champagnon, ${ }^{\ddagger}$ V. Sigaev
}

*Laboratoire de Physico Chimie des Matériaux Luminescents - UMR 5620 CNRS

Université Claude Bernard Lyon I, 12 rue Ampère 69622 Villeurbanne - France

${ }^{\dagger}$ Department of Material and Production Engineering, University of Naples Federico II, Piazzale Tecchio, Naples - Italy

${ }^{\ddagger}$ Mendeleev University of Chemical Technology of Russia, Miusskaya pl. 9, 125190 Moskow - Russia

In this paper, we present results on UV pulsed laser-induced birefringence in $\mathrm{La}_{2} \mathrm{O}_{3}$ $\mathrm{B}_{2} \mathrm{O}_{3}-\mathrm{GeO}_{2}$ (LBG) glasses. Samples are irradiated at a wavelength of $355 \mathrm{~nm}$ delivered by an Nd-YAG laser operating in the nanosecond regime. After irradiation, glasses are analyzed by Micro Raman spectroscopy and Small Angle X-ray Scattering (SAXS). Raman spectra show figures characteristic of a light polarization rotation effect in agreement with an anisotropic distribution of the scattering intensity observed by SAXS measurements. These results are interpreted as the interaction of the glass with the electromagnetic field of the UV beam (UV poling).

Keywords: pulsed laser, glass, UV poling, birefringence, Raman spectroscopy, SAXS

\section{Introduction}

Since the beginning of the eighties, photosensitivity of glasses has created a great interest for the development of integrated optoelectronic devices allowing high-speed signal processing in telecommunications. This domain is still actually subjected to many studies of research because photo written optical components in waveguides can be obtained in very compact forms and at low costs. Moreover, a few years ago, it was demonstrated that permanent refractive index variations could be induced by laser irradiations. Pulsed lasers with ultrashort pulses duration are particularly adapted for waveguide inscriptions because highly localized refractive index variations can be obtained at the focal point [1]. Laserinduced defects can be responsible for photosensitivity but volume changes such as densification are considered to have the main contribution [2, 3]. Glass properties modifications proceed via photolytic or thermal pathways which are the two principal schemes of laser-light interaction [1].

In this paper, we investigate photo-induced modifications by pulsed laser irradiations of $\mathrm{La}_{2} \mathrm{O}_{3}-\mathrm{B}_{2} \mathrm{O}_{3}-\mathrm{GeO}_{2}$ (LBG) glasses. Results are analysed in terms of birefringence in agreement with the non linear optical behaviour of the irradiated glasses. Anisotropy induced by thermal poling was previously obtained on these glasses [4]. The LBG system of the same stoichiometric composition as the stillwellite-like $\mathrm{LaBGeO}_{5}$ crystal is chosen because

e-mail : vouagner@pcml.univ-lyon1.fr 
second harmonic generation $(\mathrm{SHG}) \chi^{(2)}$ signals can be obtained from this crystal characterized by a non centrosymmetric structure [5]. SHG was recently measured in surface crystallized stillwellite-type glasses with the same composition as that of our samples [6].

\section{Experimental}

\subsection{Glasses elaboration}

LBG glasses are prepared from commercial reagent-grade powders of $\mathrm{La}_{2} \mathrm{O}_{3}, \mathrm{H}_{3} \mathrm{BO}_{3}$ and $\mathrm{GeO}_{2}$ mixed in a platinum crucible using a conventional melt-quenching method. The melt conditions are $1300-1320^{\circ} \mathrm{C}$ for 40 minutes. The melt is then quenched at room temperature. Investigated glasses are characterized by the nominal composition $25 \mathrm{La}_{2} \mathrm{O}_{3}, 25 \mathrm{~B}_{2} \mathrm{O}_{3}, 50$ $\mathrm{GeO}_{2}$.

All glasses are transparent and without any crystalline inclusions. The glass transition $\mathrm{T}_{\mathrm{g}}$ and the crystallisation $T_{p}$ temperatures, determined by differential thermal analysis (DTA), are $685^{\circ} \mathrm{C}$ and $931^{\circ} \mathrm{C}$ respectively. Previous results have shown that the LBG glass crystallized in a stillwellite-type structure [7].

\subsection{Samples preparation}

Glass samples are cut in slices of $1 \mathrm{~mm}$ thick; they are mechanically polished on both sides for optical measurements and treatments. They are then cleaned in acetone. For SAXS measurements, glasses are thinned by polishing until a thickness of about $200 \mu \mathrm{m}$ is attained to limit X-rays absorption for an optimized transmitted signal.

Before poling, glasses are annealed for 2 hours below $\mathrm{T}_{\mathrm{g}}$ to remove internal stress. It is checked that no birefringence induced by defects and/or by the polishing process remains into the samples using a polarizing microscope in a crossed polarized configuration.

\subsection{Irradiation by UV laser}

The irradiation is performed by heating the glass plate to $400^{\circ} \mathrm{C}$ in a temperatureregulated cell (Linkam TMS 92) while injecting the focused laser beam into the sample via a microscope setup equipped with a UV objective (X15) as shown in Fig.1. The third harmonic $(355 \mathrm{~nm})$ of a linearly polarized Q-switched YAG laser (repetition rate $=10 \mathrm{~Hz}$, pulse duration $=10 \mathrm{~ns}$ ) is used for the irradiation. The diameter of the focused beam is estimated to be around $10 \mu \mathrm{m}$ and the laser irradiance on the sample equal to a few tens of $\mathrm{kW} . \mathrm{cm}^{-2}$. The laser intensity and the temperature are adjusted in order to obtain marked birefringence phenomena without cracks. After different times of irradiation at high temperature, the heater is switched off and the glass plate is cooled down to room temperature. The laser irradiation is stopped only after the cooling down of the sample to room temperature. (Insert Fig. 1 about here)

A moderate photolytic radiation $(355 \mathrm{~nm}$ or $3,5 \mathrm{eV})$ is chosen for irradiation in order to avoid strong structural modifications in the glass by direct UV bond breaking [8]; this can be especially critical for the Ge-O bond present in LBG glasses : in fact, a bond energy value of $3.7 \mathrm{eV}$ can be given as a good estimation from literature data on germanosilicate glasses [9]. It can be noticed that the laser wavelength is higher than the band edge wavelength located near $260 \mathrm{~nm}$ (Fig.2). In this case, the absorption is low at the incident wavelength and is due to the glass matrix principally if there is no strong dopant absorption [1]. In fact, the 


\section{Results}

Birefringence observations on the UV irradiated samples are shown in Fig. 3. The direction of the electric field of the laser beam irradiating the glass sample is given Fig. 3a: the field is orientated along the $S_{2}$ face of the glass where birefringence effects due to the poling process can be detected. In fact, the observation of the irradiated $S_{2}$ face through crossed polarization in a microscope exhibited birefringence zones whose intensities are maximal when the electric field direction makes an angle of $45^{\circ}$ between the polarizer $(\mathrm{P})$ and analyser (A) directions (Fig. 3b). More precisely, when the sample is rotated at $360^{\circ}$ with respect to the zero position, four positions of extinction at $0^{\circ}, 90^{\circ}, 180^{\circ}$ and $360^{\circ}$ and four positions of maximal intensity at $45^{\circ}, 135^{\circ}, 225^{\circ}$ and $315^{\circ}$ are found respectively. No degradation of the birefringence is observed after several months at room temperature. (Insert Fig. 3a and $3 b$ about here)

Micro Raman measurements are performed on the laser-induced birefringence domains. For an accurate localization of these regions, glasses are observed with polarized light before probing them with the laser beam. Spectra displayed in Fig. 4 are recorded in the VH configuration at $45^{\circ}$. Two clear differences are observables between spectra obtained from these birefringent domains and those relative to the unmodified regions of the glass: an evolution of the intensity ratio of peaks located near 300 and $800 \mathrm{~cm}^{-1}$ respectively and the 
growth of a new peak close to $550 \mathrm{~cm}^{-1}$ for spectra recorded in the birefringence area. In fact, spectra performed in birefringent regions are very similar to that obtained by probing non irradiated points in the VV configuration (inset of Fig. 4). (Insert Fig. 4 about here)

As shown in Fig.5 representing the 2D SAXS profile of a UV poled LBG glass, anisotropic scattering is obtained when X-rays are focused on the $S_{2}$ face: the ellipsoidal shape of the scattering figure indicates that X-rays are not scattered in the same way in the whole cone of the angle opening; in fact, they are scattered in the two mutual perpendicular directions, parallel and perpendicular to the direction of the electric field of the laser beam [10].

(Insert Fig. 5 about here)

\section{Discussion}

The intensity variation of light with a $\pi / 2$ periodicity and the coincidence of light maxima with the electric field direction at $45^{\circ}$ respect to the polarizers are an evidence for localized birefringence into the LBG sample (Fig. 3b). This observation is in a good agreement with microRaman measurements (Fig.4): spectra recorded in the VH configuration evolve towards the VV spectra (inset of Fig.4) when domains of birefringence are probed whereas no evolution of spectra is observed during analysis of non irradiated points. Similar results were obtained previously in thermally poled LBG glasses where orientation of hyperpolarisable moieties in the bulk sample could be responsible for birefringence effects [4].

Moreover, anisotropy is clearly demonstrated by SAXS measurements performed in laser irradiated area with this marked ellipsoidal shape of diffusion visible on Fig.5. For non poled glasses, a circular shape of scattering characteristic of isotropy is observed. One can notice that this anisotropy is stronger than that observed in thermally poled LBG samples of the same composition [10].

The origin of this laser-induced anisotropy in LBG glasses can now be discussed. No external electric field is applied during irradiation: the electric field only of the laser wave is sufficient to induce birefringence effects in the glasses and the process is comparable to UV poling. The field value is estimated to be around a few $\mathrm{kV} . \mathrm{cm}^{-1}$ which is very similar to field values applied during thermal poling processes [11]. Moreover, the role of temperature seems to be critical to induce birefringence: heating of the samples during irradiation increases the glass network mobility. Several mechanisms have been proposed in literature to explain the photosensitivity of different kinds of glasses. Pre-existing defects in glasses can largely contribute to refractive index variations by a photoinduced change of absorption after UV laser irradiation according to the Kramers-Krönig relationship (color centre model) [12]. This mechanism is well-known for germanosilicates glasses characterized by a defect centre at 240 $\mathrm{nm}$. In our case, samples are excited by laser at the onset of the glass matrix absorption and no characteristic absorption band can be clearly evidenced at $355 \mathrm{~nm}$ (excitation wavelength) as shown in the inset of Fig. 1. Densification is a possible mechanism too explaining the photosensitivity of glasses. Laser-induced volume compaction or expansion can occur depending on the glass composition and structure [1]. Moreover, if chemical bonds or glass microstructure are modified under laser light irradiation, the refractive index variation will not only depends on volume modifications but also it will be strongly influenced by changes of the electronic polarisability [13]. In addition, other effects induced by laser such as stresses and changes in glass composition can also contribute to refractive index variations [1]. Until now, our results do not permit to conclude about the mechanism implied in laser-induced birefringence in LBG glasses. However, the parallel behaviour of thermal poling and UV poling leads to consider the electromagnetic field of the laser as the driven force for the birefringent effects. 


\section{Conclusion}

A permanent change in refractive index is observed after UV nanosecond laser irradiations of LBG glasses. The interaction between the electric field of the laser wave and the glass can be interpreted as a UV poling process. This local modification could lead to directly written waveguides. New experiments are in progress and will be discussed in a next paper.

\section{Acknowledgements}

The authors are grateful to J.P. Simon (ESRF-D2AM beam line) and the ESRF staff for SAXS experiments and to the CECOMO (Lyon) for the use of the Raman facilities.

\section{Bibliography}

[1] H. Ebendorff-Heidepriem, Optical Materials 25109 (2004)

[2] D.L. Williams, S.T. Davey, R. Kashyap, J.R. Armitage, B.J. Ainslie, Appl. Phys. Lett 59762 (1991)

[3] B. Poumellec, P. Niay, M. Douay, J.F. Bayon Photosensitivity and Quadratic Non Linearity in Glass Waveguides: Fundamentals and Applications 22112 (1995) OSA Technical Digest Series (Optical Society of America, Washington D.C., 1995)

[4] V. Califano, B. Champagnon, D. Vouagner, E. Fanelli, P. Pernice, V.N. Sigaev, S.V. Lotarev, D.A. Zakharkin, Physics and Chemistry of Glasses 46 n² 194 (2005)

[5] V.N. Sigaev, E.V. Lopatina, P.D. Sarkirov, A. Marotta, P. Pernice, Thermochim. Acta 286 25 (1996)

[6] Y. Takahashi, Y. Benino, T. Fujiwara, T. Komatsu, J. Appl. Phys. 89 (10) 5284 (2001)

[7] I. Kratochvilova, S. Kamba, I. Gregora, J. Petzelt, V.N. Sigaev, E.N. Smelyanskaya, V.I. Molev, Ferroelectrics 23939 (2000)

[8] J. Nishii, H. Yamanaka, H. Hosono, H. Kawazoe, Opt. Lett. 21(17) 1360 (1996)

[9] W.L. Jolly, Modern Inorganic Chemistry, McGraw-Hill, New York, (1984)

[10] V. Califano, D. Vouagner, C. Coussa, B. Champagnon, F. Chassagneux, E. Fanelli, P. Pernice, A. Aronne, V. Sigaev, J.P. Simon (to be published)

[11] O. Deparis, F.P. Mezzapesa, C. Corbari, P. G. Kazansky, K. Sakaguchi, Journal of NonCrystalline Solids 3512166 (2005)

[12] M. Douay, W.X. Xie, T. Taunay, P. Bernage, P. Niay, P. Cordier, B. Poumellec, L. Dong, J.F. Bayon, H. Poignant, E. Delevaque, Journal of Lightwave Technology 15 n 81329 (1997)

[13] B. Poumellec, P. Guenot, I. Riant, P. Sansonetti, P. Niay, P. Bernage, J.F. Bayon, Optical Materials 4441 (1995)

\section{Figures captions}

Figure 1: Experimental setup used for pulsed laser irradiation of glasses. 1: pulsed laser source; 2: microscope; 3: heating cell; $\mathrm{M}_{1}, \mathrm{M}_{2}$ : highly reflective mirrors at $355 \mathrm{~nm}$; S: glass sample; O: objective 
Figure 2: Absorption curve of LBG glasses. The arrow indicates the position of the $355 \mathrm{~nm}$ wavelength used for samples irradiation.

Figure 3: Localized laser-induced birefringence in LBG glasses observed with a polarizing microscope: (a) Electric field direction of the laser wave along the $\mathrm{S}_{2}$ face of the glass, (b) Irradiated $S_{2}$ face observed through crossed polarization showing maximal intensities for the electric field direction at $45^{\circ}$ between the polarizer (P) and analyser (A) directions. The picture covers a $2 \mathrm{~mm} \times 1.5 \mathrm{~mm}$ area. Domains of birefringence are spreading on a length scale of about $10 \mu \mathrm{m}$.

Figure 4: Raman spectra performed at $45^{\circ}$ of $\mathrm{H}$ and $\mathrm{V}$ axes, inside the glass. Spectra of the birefringent points evolve towards the VV spectra depicted in the inset.

Figure 5: Two-dimensional SAXS profile of a UV irradiated LBG glass showing the ellipsoidal shape of the figure of scattering.

Figure 1

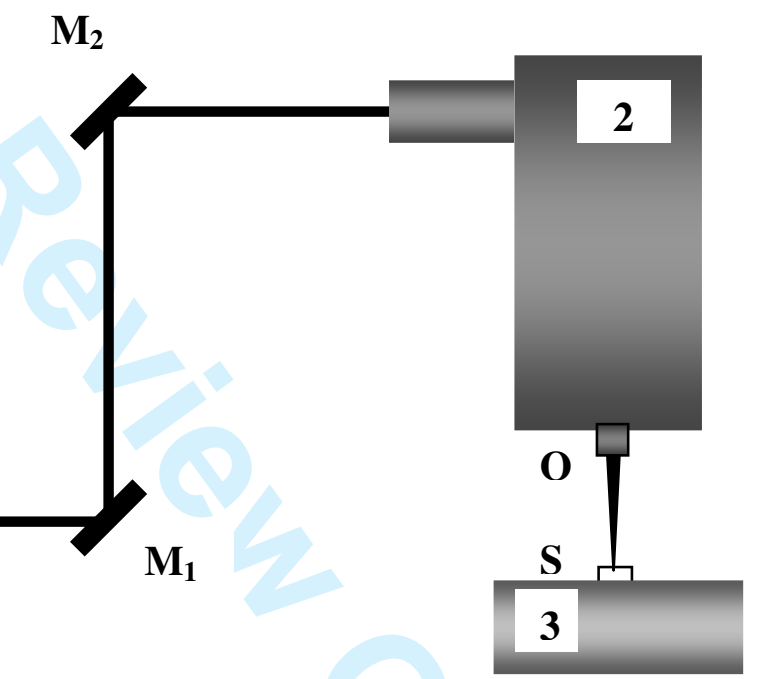

Figure 2

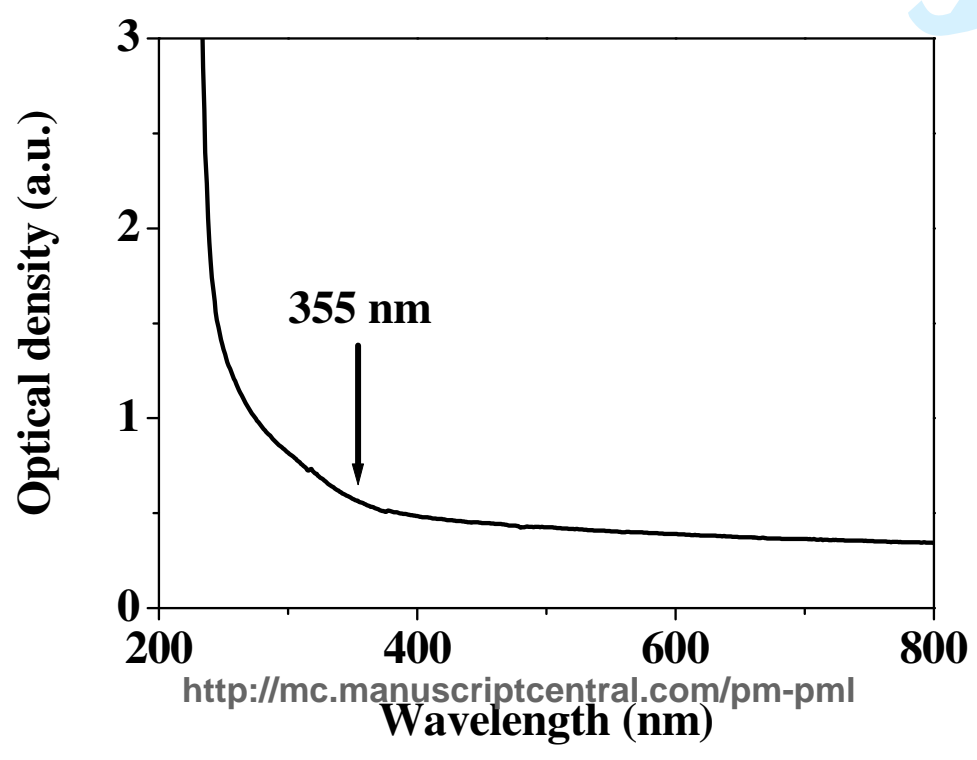


Figure 3a

Figure $3 b$
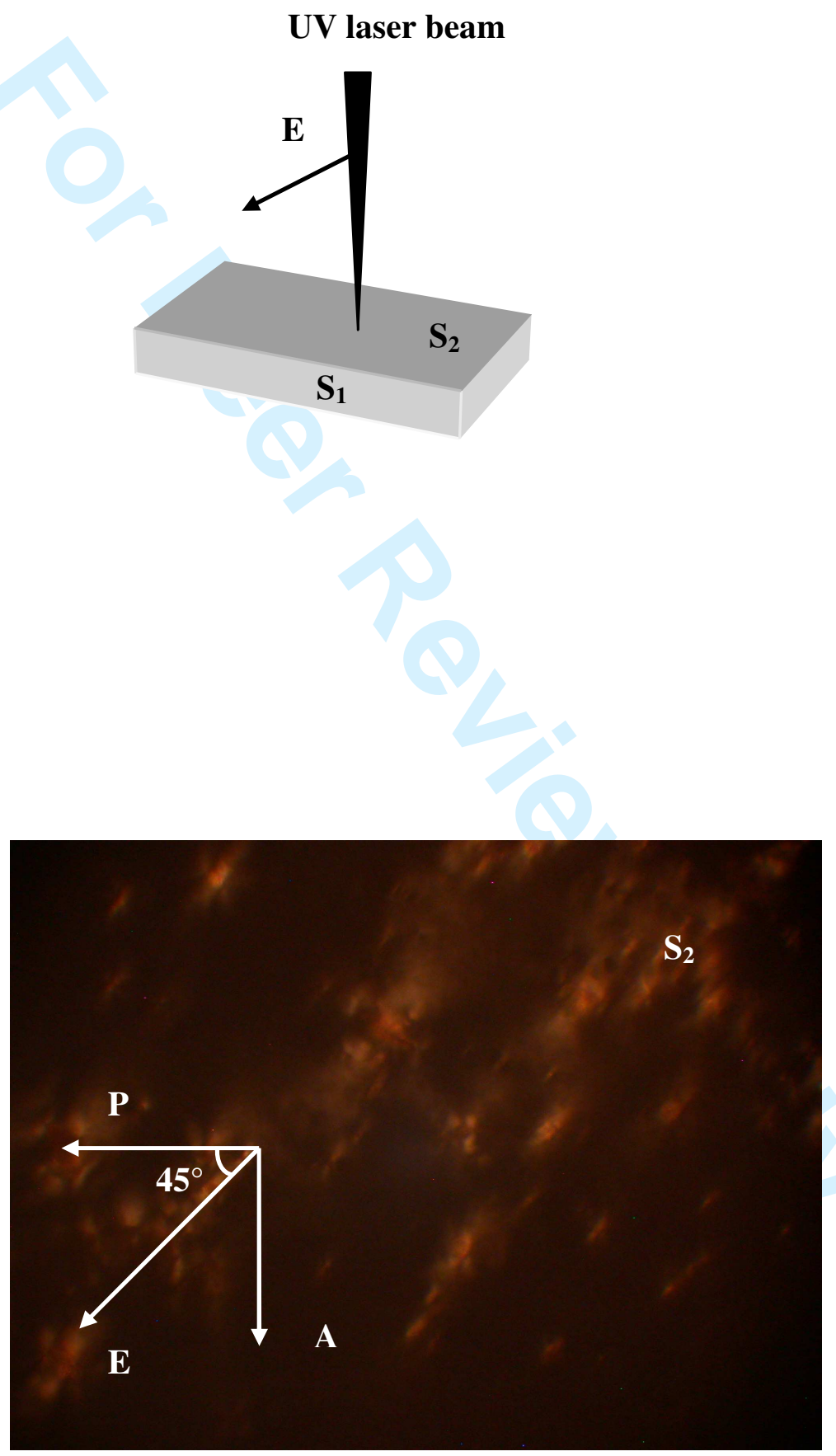
Figure 4

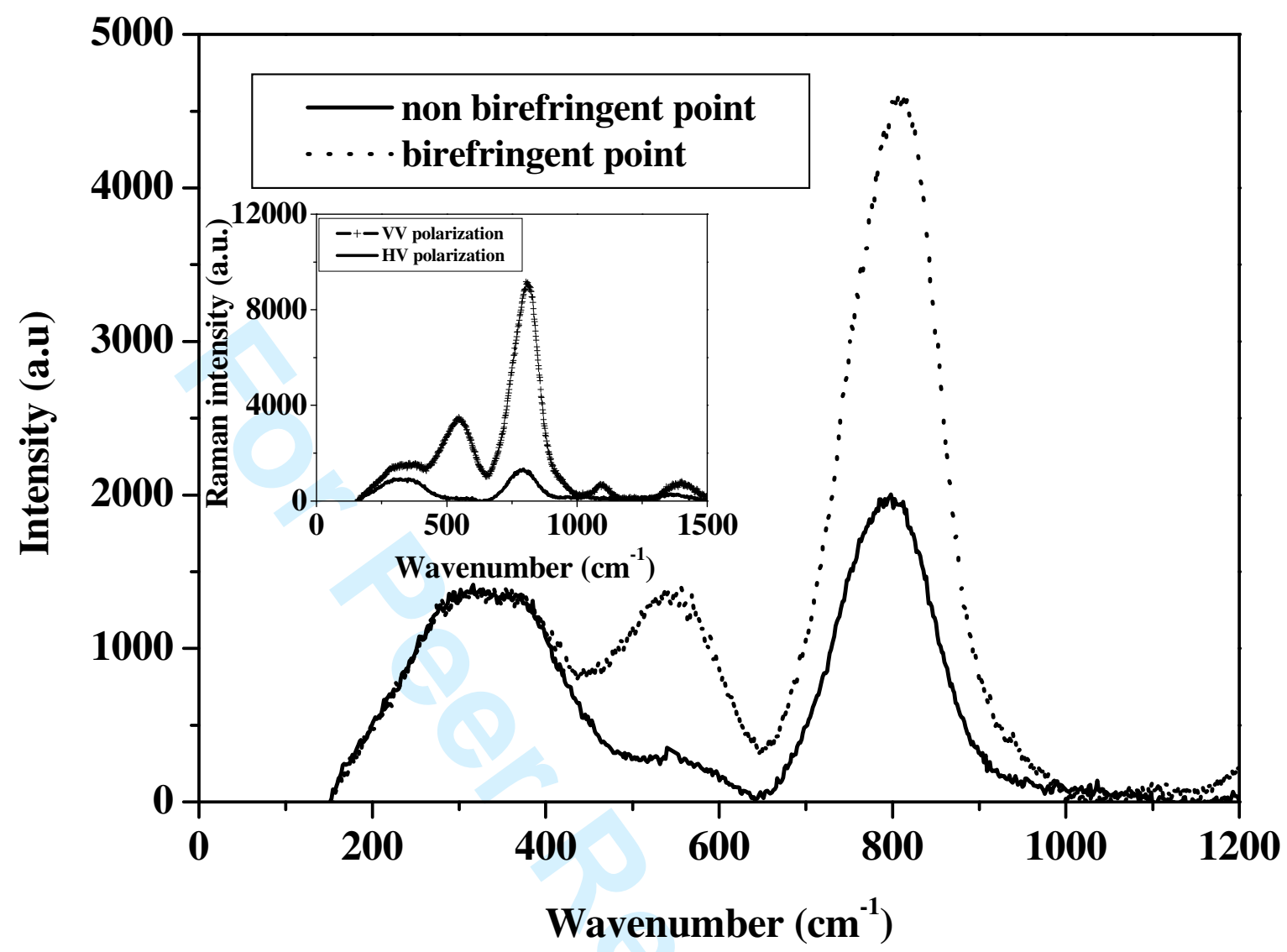

Figure 5
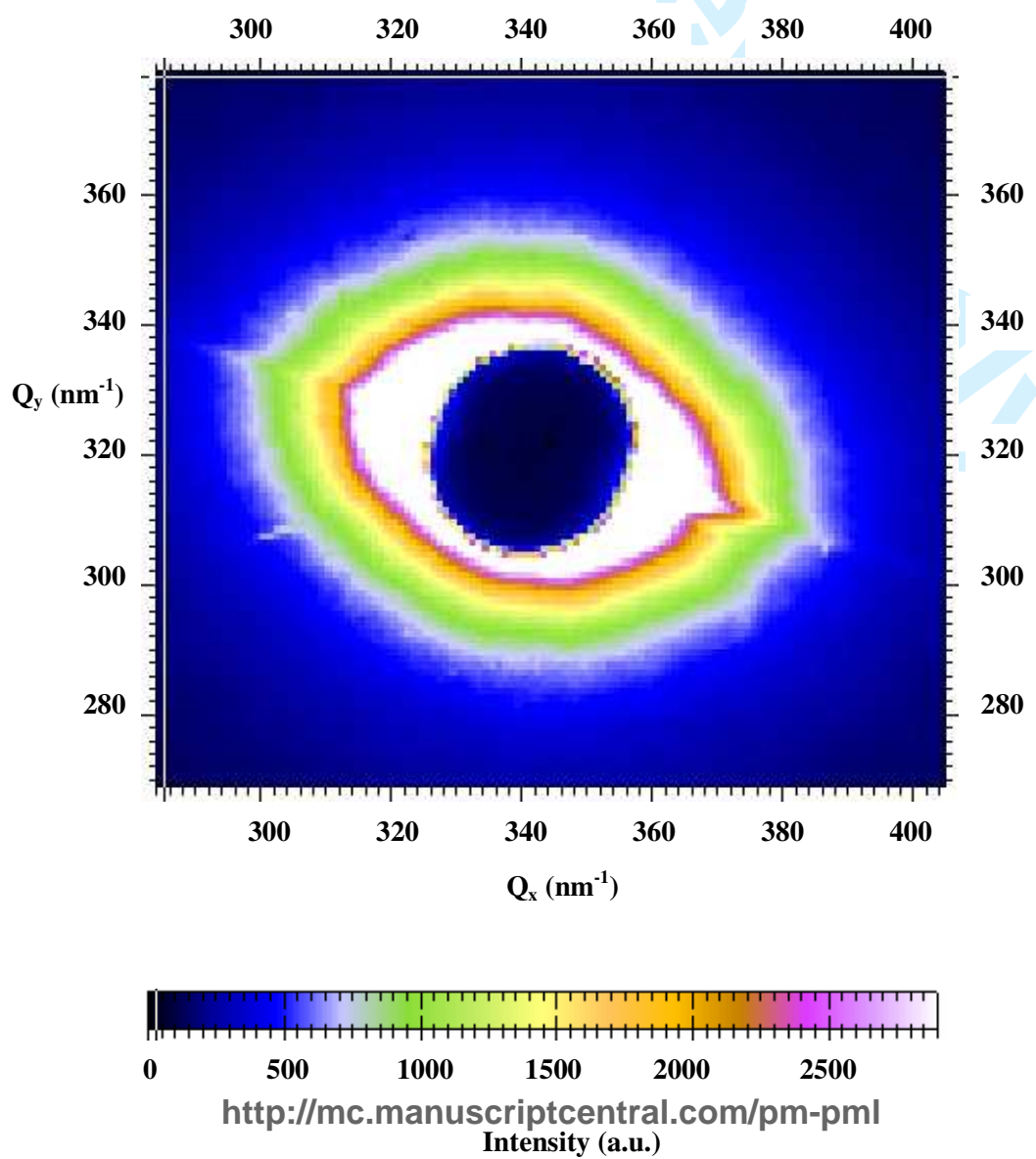